\title{
Result Analysis Suite: A Completely Automated Result Analysis Solution
}

\author{
Pankaj Sambyal ${ }^{1}$, Anamika Rustagi ${ }^{2}$, Sonia Rani ${ }^{3}$, \\ Chinab Bhudhiraja ${ }^{4}$, Bhawna Sharma ${ }^{5}$ \\ Department of Computer Science, Kalindi College, University of Delhi, India \\ 'pankaj.sambyal@kalindi.du.ac.in, 2anamikarustagi@gmail.com, ${ }^{3} 11$ soniarani@gmail.com, \\ ${ }^{4}$ chinabudhiraja@gmail.com, ${ }^{5}$ bs152763@gmail.com
}

\begin{abstract}
What gets measured, gets managed". The present paper intends to describe a one stop solution to analyze the student result data collected from the University Website automatically using the web automation technology, organize it into an efficient fashion and make it available for all stakeholders in a beautiful and intuitive way, therefore, reducing the manual task to a bare minimum. The whole system is divided into three phases - Data Collection, Re-Organization and Presentation. An automation system has been developed for raw result data collection, re-organization of the collected data and applying efficient analysis algorithms on the data locally, and in the last phase, presenting the result information to the user in an intuitive manner so as to make it easy and quick to understand and interact. Keeping the user in mind, the last phase is the most crucial one. A set of highly efficient open-source graph rendering libraries has been employed to generate interactive result infographics which are portable and can be exported for external use.
\end{abstract}

\section{Index Terms-Automation, Analysis, Infographics}

\section{INTRODUCTION}

"R ESULT analysis" refers to the process in which the result is reviewed in order to determine conclusions based on that data. The purpose of initiating this research is to minimize the man-hours needed to analyze college result and create a flexible and easy-to-use solution for all students' needs. As the time-taken by an individual to perform result analysis on each paper of a batch is about 4 hours (data from study), when scaled up to the whole college, these numbers can be ridiculously high. A versatile, expandable and economical solution is needed to perform a fundamental task such as result analysis making it easy for everyone in education community to take advantage of it. The result analysis has to be done at the end of each semester, so the Result Analysis Suite will help to reduce redundancy and keep the data organized so it becomes efficient and productive to evaluate the whole college's result with minimal human effort. It will eradicate the introduction of human error and increase accuracy and efficiency.

In the present paper, we try to summarize the application of Result Analysis Project, its different levels and the various types of infographics are also discussed like bar/column graphs, pie-charts, dynamic charts, etc.

\section{STUDY}

In the current system the teachers are supposed to go to the university website and enter the details of each student manually. These details include college, course, semester, student's name and their University roll no. If on an average there are 50 students in a batch and a teacher teaches at least 2-3 subject papers in a semester, piling up this whole information, if calculated, the time consumed for analyzing the result of a batch( $\sim 50$ students $)$ is given in Table 1 .

\begin{tabular}{|l|c|}
\hline \multicolumn{1}{|c|}{ TASK } & TIME \\
\hline $\begin{array}{l}\text { Download each student's mark } \\
\text { sheet }\end{array}$ & $\sim 1$ Hour \\
\hline $\begin{array}{l}\text { Read the result of each student from } \\
\text { university website }\end{array}$ & $\sim 1$ Hour \\
\hline $\begin{array}{l}\text { Organize the collected data in } \\
\text { spreadsheet format }\end{array}$ & $\sim 1$ Hour \\
\hline $\begin{array}{l}\text { Perform Analysis on the collected } \\
\text { data }\end{array}$ & $\sim 15$ Minutes \\
\hline Total Time & $\sim 3$ Hours 15 Minutes \\
\hline
\end{tabular}

Table 1: Time analysis of a single batch of 50 students with 2-3 papers (Data from study)

When this work is done by the teachers there is no way to compare the whole department's performance by TICs, it has to be done manually which is prone to human errors in calculation and will consume a lot of time.

\section{USER INTERFACE}

There are five levels for the user and system interactionStudent, Teacher, Teacher-In-Charge, Principal and Administration.

At Student level, the analysis of all the subjects studied so far by the user for a particular semester is provided. Caring off to Teacher level, this level describes the result data to be analyzed for a teacher teaching one or many subject papers. Inheriting all the access rights of student and teacher 
Table 1: Comparison of SEO and SEM

\begin{tabular}{|c|c|c|}
\hline & SEO & SEM \\
\hline Features & $\begin{array}{l}\text { Organic SEO and } \\
\text { Paid SEO }\end{array}$ & $\begin{array}{l}\text { Integration of SEO } \\
\text { with SMO }\end{array}$ \\
\hline Focus & $\begin{array}{l}\text { Keywords with } \\
\text { high popularity }\end{array}$ & $\begin{array}{lr}\text { Keywords } & \text { that } \\
\text { generate high } \\
\text { Return } \\
\text { Investment (ROI) }\end{array}$ \\
\hline Measure & $\begin{array}{l}\text { Number of } \\
\text { website visitors }\end{array}$ & $\begin{array}{l}\text { Number of } \\
\text { successfully } \\
\text { converted goals. }\end{array}$ \\
\hline $\begin{array}{l}\text { Landing } \\
\text { pages }\end{array}$ & $\begin{array}{l}\text { SEO pages are } \\
\text { content-heavy } \\
\text { and informative, } \\
\text { designed to use } \\
\text { keywords and } \\
\text { subject relevance } \\
\text { to rank well on } \\
\text { any search } \\
\text { engine. }\end{array}$ & $\begin{array}{l}\text { It generally leads to } \\
\text { direct, clean } \\
\text { landing pages with } \\
\text { an obvious call to } \\
\text { action and designed } \\
\text { to capture sales. }\end{array}$ \\
\hline Prediction & $\begin{array}{l}\text { It is not } \\
\text { predictable due } \\
\text { to uncertainty of } \\
\text { traffic. }\end{array}$ & $\begin{array}{l}\text { It is predictable as } \\
\text { putting enough } \\
\text { money will produce } \\
\text { high ROI }\end{array}$ \\
\hline $\begin{array}{l}\text { Skill } \\
\text { required }\end{array}$ & $\begin{array}{l}\text { Fluency in SEO } \\
\text { tools. }\end{array}$ & $\begin{array}{l}\text { Require more skills } \\
\text { than SEO. }\end{array}$ \\
\hline
\end{tabular}

level Teacher-In-Charge level is defined where they have excess to all the data (i.e. student's and teacher's personal details as well as their academic performance) regarding their department. The Principal level is provided with the combined data of the above three levels and deals with the performance of the students and departments.

The patriarch of all the levels comes at the Administration level having access to the whole system, in other words, its data and features.

\section{Data Collection}

In the existing system, the user who wants to access the details of the student needs to fill the form on University portal. This form include selecting the college name, course, semester, type of exam and entering the details like Student's name and their university roll number. If the user is a teacher then he/she needs to input his/her 3 hours approximately for the data collection only.

In the proposed system the whole result data can be collected in a database using the Web Automation technology, in which it will access the details of students from the data available on website under the student details section and automatically filling up the forms as well as downloading them for further use. This is done in less than two minutes by automation.

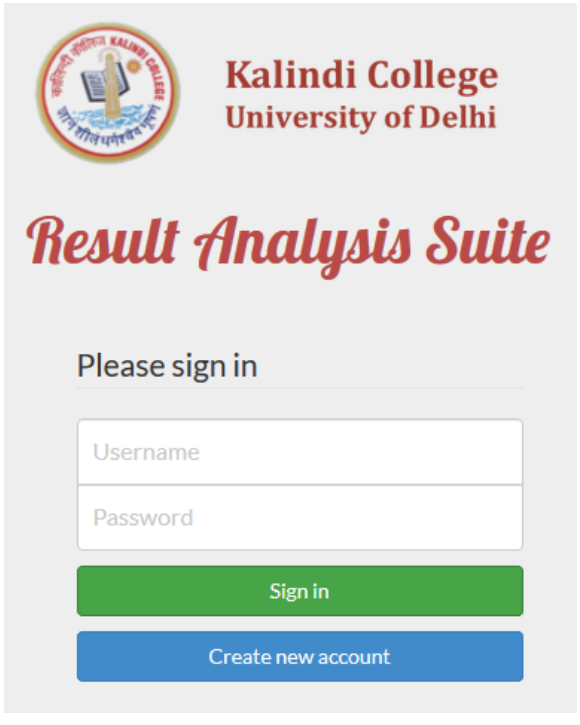

Figure 1: The Login Screen of the Front end UI

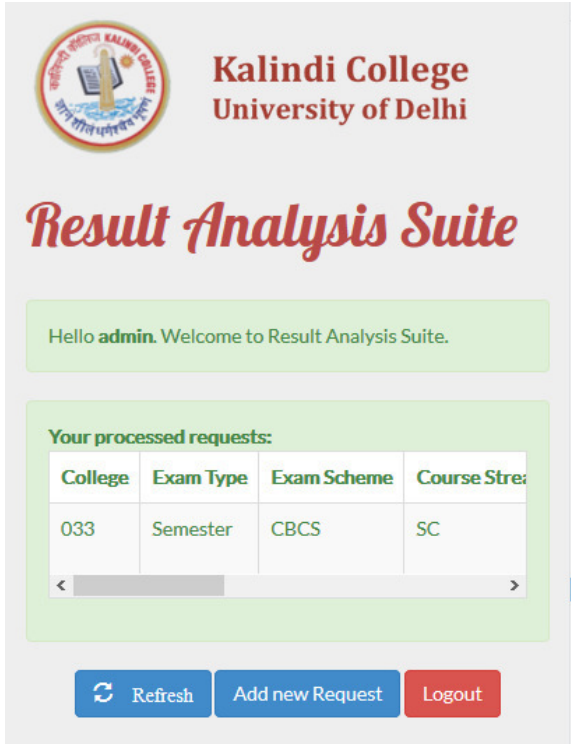

Figure 2: Second level UI for the user to check on the processing of results.

The data can be manipulated any way when it is available locally. The front-end UI along with the background Java processing engine will ensure the proper and accurate information delivery to the end user.

\section{Re-Organisation}

The data used for the analysis work is organized in databases like Student, Teacher and Paper. The original data collected from university server contains student detail and their marks statement. From this information, marks are extracted and are stored in Paper database so that analysis operations like average, count, comparisons are easily implemented. 
These databases are linked with each other by creating foreign key references and mapping the subjects with their concerned teachers, student with their subjects and so on. Integrating data from the site and organizing it into databases, enables a cumulative view of the performances of student in different subjects and helps the user at TIC and Principal level to interpret the records of their concerned departments and college respectively.

\section{Analysis}

Analysis is an art of creation through destruction and in this process inspection, cleansing, modeling and transformation of data is performed with the goal of discovering useful information, suggesting conclusions, and support decisionmaking.

In our practice of result analysis the first step depends upon the access writes of the user as level there are different levels of it. These levels include student-wise, teacher-wise, subject-wise, department-wise and overall college evaluation. If we go into further details student-wise evaluation includes his/her marks in different subjects, comparison of the performance with previous semester, his/her cumulative result, ranking in class, etc. talking about teacher analysis his subject aggregate grade/marks are calculated, pass/fail percentage of subject is calculated. For The TICs level performance of all the students and teachers of that particular department is provided and compared with each other to find out toppers in student and efficiency of teacher. The Principal and administration level user are provided with analysis features of the whole college.

\section{Presentation}

If you are the only one who "gets it", then you have failed. So for the better understanding of the analysis Infographics is used. We can display the data in a tabular form but displaying it in graphical form is more user-friendly and interesting at the same time. It makes the information simple, easily shareable, contains minimal text and have high impact on user. A simple illustration can be seen in Figure 3, where a set of test data is taken and analyzed to find the number of students in each group i.e. Grade A+, Grade A, Grade B and so on. In this example, three subject papers are taken into consideration and the user can select to see the done analysis on one or all of the papers in the generated graph. The paper and student details are available to the user if they need it.

In the second test sample (Figure 4), we can see the grade $\mathrm{A}+, \mathrm{A}, \mathrm{B}+, \mathrm{B}$ and $\mathrm{C}$ students of Computer Science and Physical Science departments.

Keeping all this in mind, different types of charts like bargraphs, pie-charts, dynamic charts are used for the representation of data. Depending on the security level of the user they provide graphical representation of their records where they can select the type of graphs and also the points of comparison. The students are allowed to access their records only, teachers can interpret their respective subject only,

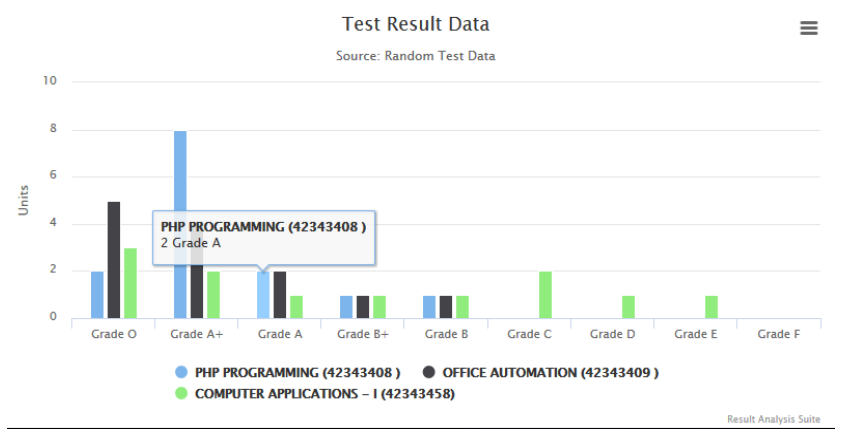

Figure 3: A test result data analysis is rendered as a bar graph.

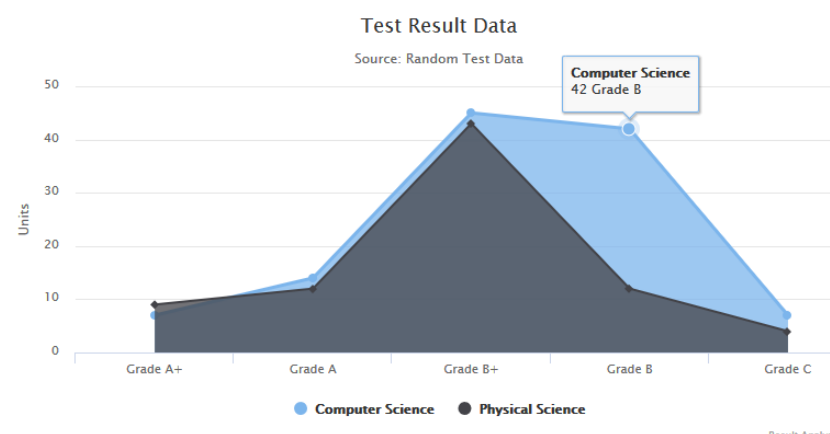

Figure 4: A test result data analysis of two departments rendered as an area map

whereas TICs can compare the output of teachers and the performance of students with each other using graphs and charts of their conveniences. Principal have access to all the graphs facilities provided to level below it. Not only comparison and analysis is done, user can also export these graphs and charts as a portable image to share or add to a comprehensive result report.

\section{Conclusion}

The Result Analysis Suite is a highly scalable solution for better understanding of performance of the student and reducing the time consumption during manual interpretation. It presents a possibility and execution of a fundamental task with no human error and $\mathbf{1 0 0 \%}$ accuracy. After thorough testing on college servers, it can be expanded to be used on a University level.

\section{REFRENCES}

[1] Lidia Ogiela, Chapter 3-Intelligent Computer Data Analysis Techniques, Editor(s): Lidia Ogiela, In Intelligent Data-Centric Systems, In Cognitive Information Systems in Management Sciences, Academic Press, 2017, Pages 25-43, ISBN 9780128038031

[2] Monitoring labor inputs: automated-data-collection model and enabling technologies Original Research Article Automation in Construction, Volume 12, Issue 2, March 2003, Pages 185-199 Ronie Navon, Eytan Goldschmidt

[3] Leigh Metcalf, William Casey, Chapter 4 - Introduction to data analysis, Editor(s): Leigh Metcalf, William Casey, In Cybersecurity and Applied Mathematics, Syngress, 2016, Pages 43-65, ISBN 9780128044520

[4] John Pirc, David DeSanto, Iain Davison, Will Gragido, 6-Data Visualization, Editor(s): John Pirc, David DeSanto, Iain Davison, Will Gragido, In Threat Forecasting, Syngress, 2016, Pages 95-103, ISBN 9780128000069 